\title{
Fuzzy Comprehensive Evaluation Method of Masonry Structure Safety Based on Grey Clustering Theory
}

\author{
Yongjun Lin ${ }^{(D},{ }^{1}$ Chitan Lin ${ }^{(D},{ }^{1}$ and Xiujiao Qiu ${ }^{2}{ }^{2}$ \\ ${ }^{1}$ School of Civil Engineering, Southwest Jiaotong University, Chengdu 610031, China \\ ${ }^{2}$ Department of Structural Engineering, Gent University, 9052 Gent, Belgium \\ Correspondence should be addressed to Xiujiao Qiu; Xiujiao.Qiu@UGent.be
}

Received 6 February 2018; Accepted 18 March 2018; Published 29 April 2018

Academic Editor: Roman Wendner

Copyright (c) 2018 Yongjun Lin et al. This is an open access article distributed under the Creative Commons Attribution License, which permits unrestricted use, distribution, and reproduction in any medium, provided the original work is properly cited.

\begin{abstract}
A comprehensive method for quantitatively appraising the safety rating of masonry structure is proposed which is able to reflect the difference in the same safety level. The analytic hierarchy process (AHP), fuzzy theory, and the grey clustering theory were applied based on the fuzzy-grey characteristics and the structural safety factors of the building system. A four-layer safety evaluation model of masonry structure considering its structural features was established by using AHP method and a three-level fuzzy comprehensive evaluation model was elaborated. Then, the weight coefficient vector of each layer was calculated according to the expert experience and existing research results. Based on the grey clustering method and the fuzzy evaluation model, the evaluation matrix of every layer was established. Finally, this method was applied to a practical masonry structure. Not only the result was in agreement with the appraisal result according to Chinese standard method, but also it quantitatively evaluates the safety grade of every factor in every layer.
\end{abstract}

\section{Introduction}

Despite the huge technological improvement, innovative materials, and building systems used all over the world, the masonry structure still represent one of the most widely used building systems worldwide. In the history of China, theGreat Wall was one of the greatest masonry structures. In 1996, China became the biggest country for producing brick, which means that, at that time, most of the residential buildings in China were masonry structure and some of them are still used now. In Europe, masonry arches and barrel vaults are quite used for centuries in different kinds of constructions, such as monuments but also in common residential buildings and bridges [1]. Masonry church is another kind of ancient building everywhere in Europe [2], not to mention the historical masonry towers and other ancient masonry buildings [3-6].

These historic masonry buildings have to be more accurately and efficiently maintained and restored nowadays, as some of them are historical heritage or they are subject to more complex loading actions or their useful life is expanded to accommodate more intensive use. For example, the masonry arch bridges carry more traffic loads nowadays than the loads for which they were designed. Consequently, it is a great of importance to evaluate the safety of these masonry buildings to find the potential dangerous factors in order to better maintain or restore them periodically.

Structural safety evaluation concludes the safety evaluation under seismic action and normal loading. Up to now, people living in the existing unreinforced masonry buildings still die after an earthquake, so that most of researches are focused on evaluating their seismic vulnerability [1-6]. Many methods to evaluate the masonry structures' seismic resistance were proposed, such as the FE upper bound limit analysis approach proposed method by Milani [2], which has been widely used on arch bridge and churches. Focus also concentrated on strengthening the masonry structure, such as using composites materials [1]. However, less research can be found on the methods for evaluating the safety under normal loading, which is closer to our daily life.

In China, the present prevailing safety evaluating method under normal loading is based on the reliability rating 
standard (GB50292-1999) [7], which only qualitatively grades the safety of the existing structure into several levels. There are other two methods proposed by C.-M. Liu and X.-L. Liu [8] and $\mathrm{Gu}$ et al. [9]. The former is a method combining quantitative and qualitative assessment and the latter one is a substructural evaluation method. However, the result of the standard method is unable to reflect the difference in the same safety level, while it is too difficult to apply the other two methods to practical structure because of their complicated evaluating procedures. In 2016, a method based on fuzzy analytic hierarchy process was put forward by Lin et al. [10]. This method is able to quantitatively evaluate the safety level ranging from the basic factor to the whole structure. However, the field data in this method were applied in his model directly after being processed by the standard method, which is ambiguous and subjective.

Analytic Hierarchy Process (AHP), which was proposed by Thomas Saaty during the 1970s, is a famous method for decision making in many fields including engineering [1113]. It is able to help the decision maker to find out the most important factors that should be prioritized by using mathematics. On the other hand, the architectural structure system is a kind of grey system $[14,15]$, of which parts information is clear while the rest is unclear [16-18]. For example, the structural safety factors such as structural failure criteria, structural damage parts, and resistance index are ambiguous and grey. For the unclear information, the grey clustering method is able to quantitatively divide them into the correct category by establishing a whitening function. It has been proved that the combined application of fuzzy mathematical method and grey clustering method on the structural assessment is not only objective but also quantitative [19-21]. Therefore, based on papers of Lin et al. [10] and Qiu [22], this paper proposed a modified method which applied grey clustering theory to process the field data obtained from any existing masonry building and then combines AHP to assess the masonry structural safety in a more objective and accurate way.

\section{The Proposed Method}

In this part, a hierarchical evaluation model was firstly constructed, which divided the factors that affect the masonry structure safety into four layers. Based on the hierarchical model, the judgment matrix of each level was determined based on expert experiences and the characteristic of masonry structure, while the weight coefficient vectors were calculated based on the judgment matrix. Then, the evaluation matrix was determined by using grey method. Finally, the comprehensive rating vector of each layer factors was calculated by fuzzy linear transformation using the three-level comprehensive evaluation method, which is a mathematical transformation coping with the weight coefficient vector and the evaluation matrix.

\subsection{Establishment of Fuzzy Comprehensive Evaluation Model}

2.1.1. Safety Evaluation Model of Masonry Structure. In order to reduce the personal influence, a hierarchical model was constructed by using AHP based on [11] as shown in Figure 1.
In this model, the factors influencing the masonry structure were divided into four layers according to the standard (GB50292-1999) [7]. Target layer stands for the whole structure; subunit layer stands for the units composed of the whole structure; subpoint layer stands for the structural members and factor layer stands for the factors influencing the safety of the structural members.

2.1.2. Principles of Fuzzy Comprehensive Evaluation Method. According to the standard (GB50292-1999) [7], the safety grades of the factor layer, subpoint layer, subunit layer, and the target layer can be divided into grades $a_{\mathrm{u}} b_{\mathrm{u}} c_{\mathrm{u}} d_{\mathrm{u}}$, $A_{\mathrm{u}} B_{\mathrm{u}} C_{\mathrm{u}} D_{\mathrm{u}}, A_{\mathrm{u}} B_{\mathrm{u}} C_{\mathrm{u}} D_{\mathrm{u}}, A_{\mathrm{su}} B_{\mathrm{su}} C_{\mathrm{su}} D_{\mathrm{su}}$, respectively, where $a_{\mathrm{u}}, A_{\mathrm{u}}$, and $A_{\mathrm{su}}$ represent the highest safety grade and $d_{\mathrm{u}}, D_{\mathrm{u}}$, and $D_{\mathrm{su}}$ are the lowest. The aim of the fuzzy comprehensive evaluation method is to quantitatively identify the grade of each factor from the factor layer to the target layer.

(1) Fuzzy Comprehensive Evaluation for Subpoint. According to formulas (1), the rating vectors $\mathbf{B}_{1 j}, \mathbf{B}_{2 j}$ of the subpoint layer can be determined through fuzzy linear transformation.

$$
\begin{array}{ll}
\mathbf{B}_{1 j}=\mathbf{W}_{1 j} * \mathbf{r}_{1 j} & j=1,2, \\
\mathbf{B}_{2 j}=\mathbf{W}_{2 j} * \mathbf{r}_{2 j} & j=1,2,3,4,
\end{array}
$$

where $\mathbf{W}_{1 j} \mathbf{W}_{2 j}, \mathbf{r}_{1 j} \mathbf{r}_{2 j}$ are the weight coefficient vectors and the evaluation matrixes of the factor layer with respect to each factor in the subpoint layer, respectively. Symbol "*” represents the generalized fuzzy synthesis operation, which is the weighted average model $\mathbf{M}(\bullet,+)$ in this paper [10].

According to the maximum subordination principle, the maximum value in the rating vectors $\mathbf{B}_{1 j}, \mathbf{B}_{2 j}$ is the corresponding grade of each factor in the subpoint layer.

(2) Fuzzy Comprehensive Evaluation for Subunit. According to the calculated rating vectors of subpoint $\mathbf{B}_{1 j}, \mathbf{B}_{2 j}$, the evaluation matrix $\mathbf{R}_{i}(i=1,2) f$ the subpoint layer can be obtained based on formulas (2).

$$
\begin{aligned}
& \mathbf{R}_{1}=\left[\begin{array}{ll}
\mathbf{B}_{11}^{T} & \mathbf{B}_{12}^{T}
\end{array}\right]^{T}, \\
& \mathbf{R}_{2}=\left[\begin{array}{llll}
\mathbf{B}_{21}{ }^{T} & \mathbf{B}_{22}{ }^{T} & \mathbf{B}_{23}{ }^{T} & \mathbf{B}_{24}{ }^{T}
\end{array}\right]^{T} .
\end{aligned}
$$

Then, the rating vectors of subunit layer $\mathbf{B}_{i}$ can be determined by formula (3).

$$
\mathbf{B}_{i}=\mathbf{W}_{i} * \mathbf{R}_{i} \quad i=1,2,
$$

where $\mathbf{W}_{i}$ are the weight coefficient vectors of subpoint layer. Also, the safety grade value of each factor in the subunit layer is the maximum value in $\mathbf{B}_{i}$.

(3) Fuzzy Comprehensive Evaluation for the Whole Structure. Similarly, the evaluation matrix $\mathbf{R}$ of the subunit can be obtained according to its rating vector $\mathbf{B}_{i}$ based on formula (4).

$$
\mathbf{R}=\left[\begin{array}{ll}
\mathbf{B}_{1}^{T} & \mathbf{B}_{2}^{T}
\end{array}\right]
$$




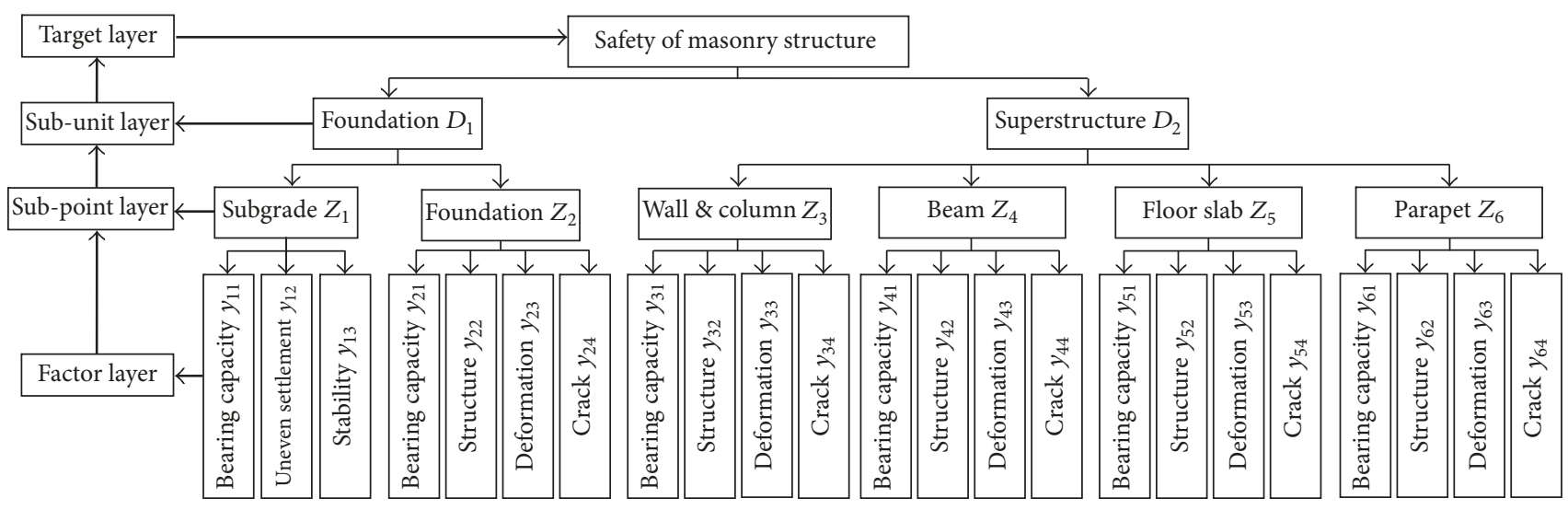

FIGURE 1: Hierarchy evaluation model of the masonry structure safety.

Then, according to the weight coefficient vector $\mathbf{W}$ of subunit layer, the fuzzy linear transformation of $\mathbf{R}$ is performed based on formula (5) to obtain the evaluation grade vector $\Delta$ of the whole structure.

$$
\Delta=\mathbf{W} * \mathbf{R} .
$$

Again, according to the principle of maximum membership, the grade corresponding to the maximum value in $\Delta$ is the safety grade of the whole structure.

2.2. Determination of Weight Coefficient Vector. The most significant step of AHP method is to construct the judgment matrix which uses pairwise comparisons to judge the importance of one element over another. There are many methods to obtain the judgment matrix. In this paper, the $e^{0 / 5} \sim e^{8 / 5}$ scale method was adopted for its better rank preservation, uniformity, and homogeneity [23]. In this method, nine scales are included. When two factors are compared, $e^{0 / 5}, e^{2 / 5}, e^{4 / 5}$, $e^{6 / 5}$, and $e^{8 / 5}$ represent that the former factor is equally important, more important, obviously important, strongly important, and extremely important than the latter factor, respectively, and $e^{1 / 5}, e^{3 / 5}, e^{5 / 5}$, and $e^{7 / 5}$ mean that the importance is between the adjacent judgments mentioned above.

By resolving the maximum eigenvalue of the judgment matrix, the eigenvector for the maximum eigenvalue can be found. The weight coefficient vector is the eigenvector after normalization. Through this method, we can get the weight coefficient vector of each layer.

However, in order to avoid the occurrence of logical errors and to ensure the accuracy of the weight of each factor, the incompatibility of the constructed judgment matrix must satisfy the condition below.

$$
I_{\mathrm{CR}}<0.1
$$

where

$$
I_{\mathrm{CR}}=\frac{\left(\lambda_{\max }-n\right)}{(n-1)},
$$

where $I_{\mathrm{CR}}$ is the incompatibility and $\lambda_{\max }$ is the maximum eigenvalue of the judgment matrix. $n$ is the dimension of the
TABLE 1: The judgment matrix of subunit layer.

\begin{tabular}{lcc}
\hline Subunit layer & Foundation & Superstructure \\
\hline Foundation & $e^{0 / 5}$ & $e^{1 / 5}$ \\
Superstructure & $e^{-1 / 5}$ & $e^{0 / 5}$
\end{tabular}

TABLE 2: The judgment matrix of foundation.

\begin{tabular}{lcc}
\hline Subpoint layer & Subgrade & Foundation \\
\hline Subgrade & $e^{0 / 5}$ & $e^{1 / 5}$ \\
Foundation & $e^{-1 / 5}$ & $e^{0 / 5}$ \\
\hline
\end{tabular}

judgment matrix. If the constructed judgment matrix cannot meet the condition, adjustment should be done until it meets.

2.2.1. Weight Coefficient Vector of Subunit Layer. It can be seen from Figure 1 that the whole masonry structure was divided into two subunits including foundation and superstructure. The judgment matrix of the subunit layer could be obtained by mutual comparing based on the questionnaire results from experienced experts, as shown in Table 1. By using the method above, the weight vector of the subunit is $\mathbf{W}=\left[\begin{array}{ll}0.55 & 0.45\end{array}\right]$.

2.2.2. Weight Coefficient Vector of Subpoint Layer. Similarly, the judgment matrixes of the subpoint layer factors are shown in Tables 2 and 3. The weight coefficient vectors of foundation and superstructure are $\mathbf{W}_{1}=\left[\begin{array}{ll}0.55 & 0.45\end{array}\right], \mathbf{W}_{2}=$ $\left[\begin{array}{llll}0.433 & 0.331 & 0.163 & 0.073\end{array}\right]$, respectively.

2.2.3. Weight Coefficient Vector of Factor Layer. The judgment matrixes of the factor layer factors are shown in Tables 4 and 5. The weight coefficient vectors of the subgrade and foundation are $\mathbf{W}_{11}=\left[\begin{array}{lll}0.207 & 0.058 & 0.735\end{array}\right], \mathbf{W}_{12}=$ $\left[\begin{array}{llll}0.581 & 0.124 & 0.046 & 0.249\end{array}\right]$, respectively.

The judgment matrixes of the wall and column, beam, floor slab, and parapet are the same as the foundation, as well as their weight coefficient vector, which means that $\mathbf{W}_{21}=$ $\mathbf{W}_{22}=\mathbf{W}_{23}=\mathbf{W}_{24}=\left[\begin{array}{llll}0.581 & 0.124 & 0.046 & 0.249\end{array}\right]$. 
TABLE 3: The judgment matrix of superstructure.

\begin{tabular}{|c|c|c|c|c|}
\hline Subpoint layer & Wall and column & Beam & Floor slap & Parapet \\
\hline Wall and column & $e^{0 / 5}$ & $e^{2 / 5}$ & $e^{5 / 5}$ & $e^{8 / 5}$ \\
\hline Beam & $e^{-2 / 5}$ & $e^{0 / 5}$ & $e^{4 / 5}$ & $e^{7 / 5}$ \\
\hline Floor slap & $e^{-5 / 5}$ & $e^{-4 / 5}$ & $e^{0 / 5}$ & $e^{4 / 5}$ \\
\hline Parapet & $e^{-8 / 5}$ & $e^{-7 / 5}$ & $e^{-4 / 5}$ & $e^{0 / 5}$ \\
\hline
\end{tabular}

TABLE 4: The judgment matrix of subgrade.

\begin{tabular}{lccc}
\hline Evaluation factors & Bearing capacity & Uneven settlement & Stability \\
\hline Bearing capacity & $e^{0 / 5}$ & $e^{5 / 5}$ & $e^{-5 / 5}$ \\
Uneven settlement & $e^{-5 / 5}$ & $e^{0 / 5}$ & $e^{-8 / 5}$ \\
Stability & $e^{5 / 5}$ & $e^{8 / 5}$ & $e^{0 / 5}$ \\
\hline
\end{tabular}

TABLE 5: The judgment matrix of foundation.

\begin{tabular}{|c|c|c|c|c|}
\hline Evaluation factors & Bearing capacity & Structure & Deformation & Crack \\
\hline Bearing capacity & $e^{0 / 5}$ & $e^{8 / 5}$ & $e^{5 / 5}$ & $e^{3 / 5}$ \\
\hline Structure & $e^{-8 / 5}$ & $e^{0 / 5}$ & $e^{-3 / 5}$ & $e^{-6 / 5}$ \\
\hline Deformation & $e^{-5 / 5}$ & $e^{3 / 5}$ & $e^{0 / 5}$ & $e^{-1 / 5}$ \\
\hline Crack & $e^{-3 / 5}$ & $e^{6 / 5}$ & $e^{1 / 5}$ & $e^{0 / 5}$ \\
\hline
\end{tabular}

2.3. Construction of Evaluation Matrix of Factor Layer Based on Grey Clustering Method. The clustering coefficients calculated by the grey clustering method can reflect the membership degree of clustering targets to a certain security level. According to the hierarchy model of masonry, the grey clustering method was used to determine the clustering coefficient of each factor in the factor layer. Based on the clustering coefficient, the judgment matrix $\mathbf{r}$ of the factor layer of subpoint factors was established.

The essence of grey method is to classify the clustering index with regard to a certain clustering target among the certain grey class. According to the subpoint layer in Figure 1, there are six clustering targets including subgrade, foundation, wall and column, beam, floor slab, and parapet. According to the factor layer, there are seven clustering indexes including the bearing capability of all clustering targets, deformation (uneven settlement) of subgrade, deformation of other targets, structure of all targets, crack of the foundation, crack of other targets, and stability of subgrade. Finally, there are four grey classes including $a_{\mathrm{u}}, b_{\mathrm{u}}, c_{\mathrm{u}}$, and $d_{\mathrm{u}}$ for all the clustering indexes.

\subsubsection{Evaluation Criteria of Clustering Indexes of the Subgrade}

(1) Evaluation Criteria of Clustering Indexes of the Subgrade. The evaluation criteria of the clustering indexes of subgrade were given in [9] and "Code for Design of Building Foundation" (GB50007-2011) [24], as shown in Table 6. Uneven settlement means that the settlement height difference is divided by the distance between the two measuring points.

(2) Evaluation Criteria of Clustering Indexes of Other Clustering Targets. The evaluation criteria for clustering indexes (bearing capacity, deformation, cracks, and structure) of the foundation, column and wall, beam, floor slab, and parapet were given in [9] and "Code for Design of Masonry Structures" (GB50003-2011) [25], as shown in Table 7. The values in the brackets in the column of cracks are the values of the evaluation criteria for foundation cracks.

Bearing in mind that the size and the unit of the sample data of clustering indexes may be different, the dimensionless method is necessary to eliminate the impact of the data dimension. Thus, except the evaluation criteria of bearing capacity, structure, and the subgrade stability whose values are already between 0 and 1, the criteria of other four clustering indexes were transferred to dimensionless form; the results are shown in Table 8.

2.3.2. Whitening Weight Function of the Clustering Index. According to the dimensionless evaluation criteria of each clustering index, we constructed the whitening right function for each clustering index. There are four kinds of whitening weight functions (the critical function, the upper limit function, the moderate measure function, and the lower limit function). For those clustering indexes, such as carrying capacity, structure, and subgrade stability whose large data is better, the whitening weight functions of upper limit measurement were adopted. For those indexes whose small data is better, such as deformation and cracks, the whitening weight functions of lower limit measurement were applied.

$f_{j}^{k}(x)$ are the whitening weight functions for the clustering indexes, where $k(1,2,3,4)$ denotes grey classes relating to $a_{\mathrm{u}}, b_{\mathrm{u}}, c_{\mathrm{u}}$, and $d_{\mathrm{u}}$, respectively; $j(1,2,3,4,5,6,7)$ refers to the bearing capacity, deformation of subgrade, deformation of other clustering targets, structure, cracks of foundation, 
TABLE 6: Evaluation criteria of clustering indexes of the subgrade.

\begin{tabular}{lccc}
\hline Grey class & $\begin{array}{c}\text { Bearing capacity } \\
f_{a} / p_{k} \text { or } f_{a} / p_{k \max }\end{array}$ & Deformation & Stability \\
\hline$a_{\mathrm{u}}$ & $\geq 1.0$ & $\leq 0.001$ & $\begin{array}{c}\text { The foundation is very stable, no signs of sliding or no sliding history. } \\
b_{\mathrm{u}}\end{array}$ \\
& $\geq 0.95$ & $\leq 0.002$ & $\begin{array}{c}\text { There was a history of local sliding, which stopped after treatment, and according } \\
\text { to recent evaluation, the foundation will not slip under normal conditions. } \\
c_{\mathrm{u}}\end{array}$ \\
$d_{\mathrm{u}}$ & $<0.90$ & $>0.005$ & $\begin{array}{c}\text { There was a slide, which is stopped now, but it may still slip if the inducing factor } \\
\text { is touched. }\end{array}$ \\
\hline
\end{tabular}

Note. $p_{k}$ : the standard combination value for average pressure of foundation base; $p_{k \text { max }}$ : the standard combination value for maximum pressure of the edge of foundation base; and $f_{a}$ : the characteristic value of the bearing capacity of foundation. ${ }^{(1)}$ Where the deformation refers to uneven settlement.

TABLE 7: Evaluation criteria of clustering indexes of the foundation, column and wall, beam, floor slab, and parapet.

\begin{tabular}{|c|c|c|c|c|c|}
\hline \multirow[b]{2}{*}{ Grey class } & \multirow{2}{*}{$\begin{array}{l}\text { Bearing capacity } \\
R /\left(\gamma_{0} S\right)\end{array}$} & \multirow{2}{*}{$\begin{array}{l}\text { Deformation } \\
\quad(\mathrm{mm})\end{array}$} & \multirow{2}{*}{$\begin{array}{l}\text { Cracks } \\
(\mathrm{mm})\end{array}$} & \multicolumn{2}{|c|}{ Structure } \\
\hline & & & & Ratio of height to thickness & $\begin{array}{l}\text { Connections and other } \\
\text { structures }\end{array}$ \\
\hline $\begin{array}{l}a_{\mathrm{u}} \\
b_{\mathrm{u}}\end{array}$ & $\begin{array}{l}\geq 1.0 \\
\geq 0.95\end{array}$ & $\begin{array}{l}\leq 10 \\
\leq 30\end{array}$ & $\begin{array}{l}\leq 0(0.2) \\
\leq 5(0.3)\end{array}$ & $\begin{array}{l}\text { Meets or does not meet the } \\
\text { current design code }\end{array}$ & $\begin{array}{l}\text { Does not meet the requirements } \\
\text { of the country's current design } \\
\text { code and exceeds the prescribed } \\
\text { limit of } 10 \%\end{array}$ \\
\hline $\begin{array}{l}c_{\mathrm{u}} \\
d_{\mathrm{u}}\end{array}$ & $\begin{array}{l}\geq 0.90 \\
<0.85\end{array}$ & $\begin{array}{l}\leq 60 \\
>90\end{array}$ & $\begin{array}{l}\leq 10(0.4) \\
\leq 15(0.5)\end{array}$ & $\begin{array}{l}\text { Accurate connection mode } \\
\text { and the structure meet the } \\
\text { current code, with no } \\
\text { defect or only partial } \\
\text { surficial defects and } \\
\text { working properly }\end{array}$ & $\begin{array}{l}\text { Wrong connection mode with } \\
\text { serious defects in the structure } \\
\text { which have caused deformation, } \\
\text { loosening, cracking, and } \\
\text { displacement or have caused } \\
\text { other damage }\end{array}$ \\
\hline
\end{tabular}

Note. $R$ : the design value of resistance; $S$ : the design value of action effect; and $\gamma_{0}$ : the structural importance factor.

cracks of other clustering targets, and stability of subgrade, respectively, and $x$ is the sample value.

The whitening weight functions of bearing capacity, structure, and subgrade stability corresponding to 4 grey classes are expressed as functions (8a), (8b), (8c), and (8d).

Whitening weight functions for grey class $a_{\mathrm{u}}$

$$
f_{j}^{1}(x)= \begin{cases}0 & x \notin\left[\alpha_{1},+\infty\right) \\ \frac{x-\alpha_{1}}{1-\alpha_{1}} & x \in\left[\alpha_{1}, 1.0\right] \\ 1 & x \in[1.0,+\infty) .\end{cases}
$$

Whitening weight function for grey class $b_{\mathrm{u}}$

$$
f_{j}^{2}(x)= \begin{cases}0 & x \notin\left[\alpha_{2}, 1.0\right] \\ \frac{x-\alpha_{2}}{\alpha_{1}-\alpha_{2}} & x \in\left[\alpha_{2}, \alpha_{1}\right] \\ \frac{1.0-x}{1.0-\alpha_{1}} & x \in\left[\alpha_{1}, 1.0\right] .\end{cases}
$$

Whitening weight function for grey class $c_{\mathrm{u}}$

$$
f_{j}^{3}(x)= \begin{cases}0 & x \notin\left[\alpha_{3}, \alpha_{1}\right] \\ \frac{x-\alpha_{3}}{\alpha_{2}-\alpha_{3}} & x \in\left[\alpha_{3}, \alpha_{2}\right] \\ \frac{\alpha_{1}-x}{\alpha_{1}-\alpha_{2}} & x \in\left[\alpha_{2}, \alpha_{1}\right] .\end{cases}
$$

Whitening weight function for grey class $d_{\mathrm{u}}$

$$
f_{j}^{4}(x)= \begin{cases}0 & x \notin\left(-\infty, \alpha_{2}\right] \\ \frac{\alpha_{2}-x}{\alpha_{2}-\alpha_{3}} & x \in\left[\alpha_{3}, \alpha_{2}\right] \\ 1 & x \in\left(-\infty, \alpha_{3}\right],\end{cases}
$$

where $j=1,4,7 ; \alpha_{1}, \alpha_{2}, \alpha_{3}$ are the transition coefficients of weight functions, where values are $0.95,0.9$, and 0.85 , respectively, for bearing capacity and $0.75,0.5$, and 0.25 , respectively, for structure and stability.

The whitening weight functions of deformation of subgrade and other clustering targets, cracks of foundations, and other clustering targets corresponding to four grey classes are expressed as expressions (9a), (9b), (9c), and (9d).

Whitening weight function for grey class $a_{\mathrm{u}}$

$$
f_{j}^{1}(x)= \begin{cases}0 & x \notin\left(-\infty, \beta_{2}\right] \\ 1 & x \in\left(-\infty, \beta_{1}\right] \\ \frac{\beta_{2}-x}{\beta_{2}-\beta_{1}} & x \in[1.0,+\infty) .\end{cases}
$$




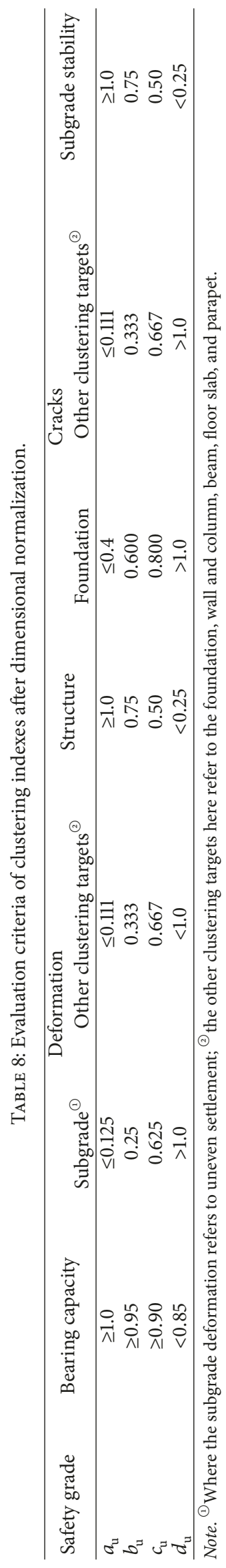


Whitening weight function for grey class $b_{\mathrm{u}}$

$$
f_{j}^{2}(x)= \begin{cases}0 & x \notin\left[\beta_{1}, \beta_{3}\right] \\ \frac{x-\beta_{1}}{\beta_{2}-\beta_{1}} & x \in\left[\beta_{1}, \beta_{2}\right] \\ \frac{\beta_{3}-x}{\beta_{3}-\beta_{2}} & x \in\left[\beta_{2}, \beta_{3}\right] .\end{cases}
$$

Whitening weight function for grade class $c_{\mathrm{u}}$

$$
f_{j}^{3}(x)= \begin{cases}0 & x \notin\left[\beta_{2}, 1.0\right] \\ \frac{x-\beta_{2}}{\beta_{3}-\beta_{2}} & x \in\left[\beta_{2}, \beta_{3}\right] \\ \frac{1.0-x}{1.0-\beta_{3}} & x \in\left[\beta_{3}, 1.0\right] .\end{cases}
$$

Whitening weight function for grade class $d_{\mathrm{u}}$

$$
f_{j}^{4}(x)= \begin{cases}0 & x \notin\left[\beta_{3},+\infty\right) \\ \frac{x-\beta_{3}}{1.0-\beta_{3}} & x \in\left[\beta_{3}, 1.0\right] \\ 1 & x \in[1.0,+\infty),\end{cases}
$$

where $j=2,3,5,6 ; \beta_{1}, \beta_{2}, \beta_{3}$ are the transition coefficients of weight functions, which values are $0.125,0.5$, and 0.625 , respectively, for subgrade deformation, $0.4,0.6$, and 0.8 , respectively, for cracks of foundation and $0.111,0.333$, and 0.667 , respectively, for deformation and cracks of other clustering targets.

2.3.3. Establishment of Evaluation Matrix for Factor Layer. According Table 8, the weight coefficients of grey classes of various clustering indexes were calculated according to formula (10).

$$
\eta_{j}^{k}=\frac{\lambda_{j}^{k}}{\sum_{j=1}^{7} \lambda_{j}^{k}},
$$

where $\eta_{j}^{k}$ are weight coefficients; $\lambda_{j}^{k}$ are numerical evaluation values in Table 8 of each grey class of clustering indexes. The meaning of $k$ and $j$ are the same as mentioned above.

Taking the grey class $a_{\mathrm{u}}$ as an example, the numerical evaluation values of evaluation of grey class $a_{\mathrm{u}}$ for all indexes are $1.0,0.125,0.111,1.0,0.4,0.111$, and 1.0 , respectively. The weight coefficient $\eta_{1}^{1}$ of grey class $a_{\mathrm{u}}$ of the bearing capacity could be calculated according to formula (10) as

$$
\begin{aligned}
\eta_{1}^{1} & =\frac{1.0}{1.0+0.125+0.111+1.0+0.4+0.111+1.0} \\
& =0.267 .
\end{aligned}
$$

Similarly, the weight coefficients of grey class $a_{\mathrm{u}}$ of other clustering indexes are $\eta_{2}^{1}=0.033, \eta_{3}^{1}=0.030, \eta_{4}^{1}=0.267, \eta_{5}^{1}=$ $0.106, \eta_{6}^{1}=0.030$, and $\eta_{7}^{1}=0.260$, respectively. The weight coefficients of other grey classes are shown in Table 9.
After determining the whitening value and the weight coefficients, the clustering coefficients that represent the membership degree to a certain grey class of the clustering indexes were calculated by formula (12).

$$
\sigma_{j}^{k}=\sum_{i=1}^{m} f_{j}^{k}\left(x_{i j}\right) \cdot \eta_{j}^{k},
$$

where $\sigma_{j}^{k}$ are clustering coefficients of clustering indexes; $i$ is the sample number; $m$ is the total detection sample number of index $j ; x_{i j}$ is the dimensionless value of sample $i$. The evaluation matrix of the factor layer was obtained after the dimensional normalization of the clustering coefficients. For example, the comprehensive evaluation matrix of clustering indexes of subgrade including bearing capacity, deformation, and stability is

$$
\left[\begin{array}{ccccc}
\frac{\sigma_{1}^{1}}{\sum_{k=1}^{4} \sigma_{1}^{k}} & \frac{\sigma_{1}^{2}}{\sum_{k=1}^{4} \sigma_{1}^{k}} & \frac{\sigma_{1}^{3}}{\sum_{k=1}^{4} \sigma_{1}^{k}} & \frac{\sigma_{1}^{4}}{\sum_{k=1}^{4} \sigma_{1}^{k}} \\
\frac{\sigma_{2}^{1}}{\sum_{k=1}^{4} \sigma_{2}^{k}} & \frac{\sigma_{2}^{2}}{\sum_{k=1}^{4} \sigma_{2}^{k}} & \frac{\sigma_{2}^{3}}{\sum_{k=1}^{4} \sigma_{2}^{k}} & \frac{\sigma_{2}^{4}}{\sum_{k=1}^{4} \sigma_{2}^{k}} \\
\frac{\sigma_{7}^{1}}{\sum_{k=1}^{4} \sigma_{7}^{k}} & \frac{\sigma_{7}^{2}}{\sum_{k=1}^{4} \sigma_{7}^{k}} & \frac{\sigma_{7}^{3}}{\sum_{k=1}^{4} \sigma_{7}^{k}} & \frac{\sigma_{7}^{4}}{\sum_{k=1}^{4} \sigma_{7}^{k}}
\end{array}\right],
$$

where $k$ is the grey class. Similarly, the comprehensive evaluation matrixes $\mathbf{r}_{12}, \mathbf{r}_{21}, \mathbf{r}_{22}, \mathbf{r}_{23}$, and $\mathbf{r}_{24}$ of the foundation, column and wall, beam, floor slab, and parapet were obtained.

2.4. Evaluation Process. According to the data strength and structural geometrical dimensions of the masonry structure with the field data of deformation, structure, fracture, and damage of the masonry structure, the fuzzy comprehensive evaluation method based on grey theory was used to evaluate the safety of the whole structure. The basic flow is shown in Figure 2.

Based on the maximum membership principle, the safety level of each subpoint, subunit, and the whole structure could be determined quantitatively after obtaining the rating vector of the subpoint, the subunit, and the target layers.

\section{Validation of the Method}

The plane layout of a four-floor brick-concrete residential building with a size of $15.8 \mathrm{~m} * 11.2 \mathrm{~m} * 12.0 \mathrm{~m}$ in China is shown in Figure 3. It was built in 1980s. According to the current "Code for Seismic Design of Buildings" (GB 500112010) [26], its seismic fortification intensity is 7 and the design ground motion parameter is $0.1 \mathrm{~g}$. The seismic group was designed as the third group. Through site detection, the strength of materials is shown in Table 10.

3.1. Establishment of Evaluation Matrix of the Factor Layer. The strength of materials and structural geometrical dimensions of the structure, as well as the data of deformation, structure, crack, damage, and so on, were obtained by site detection. The structural damage is shown in Figure 4. After 


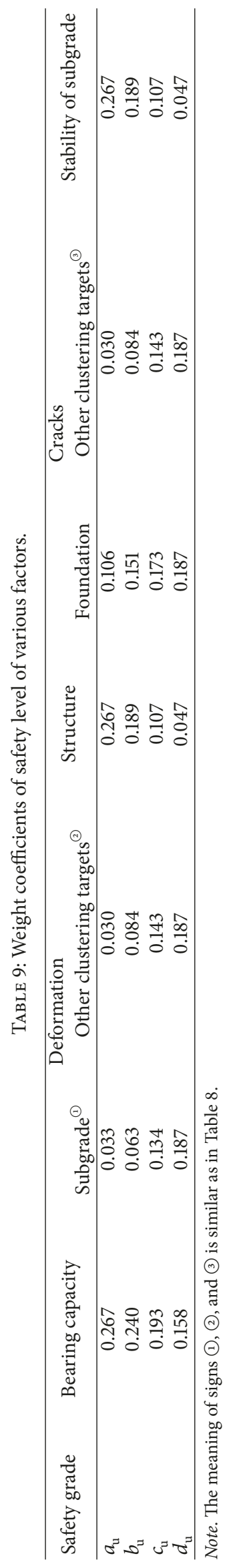




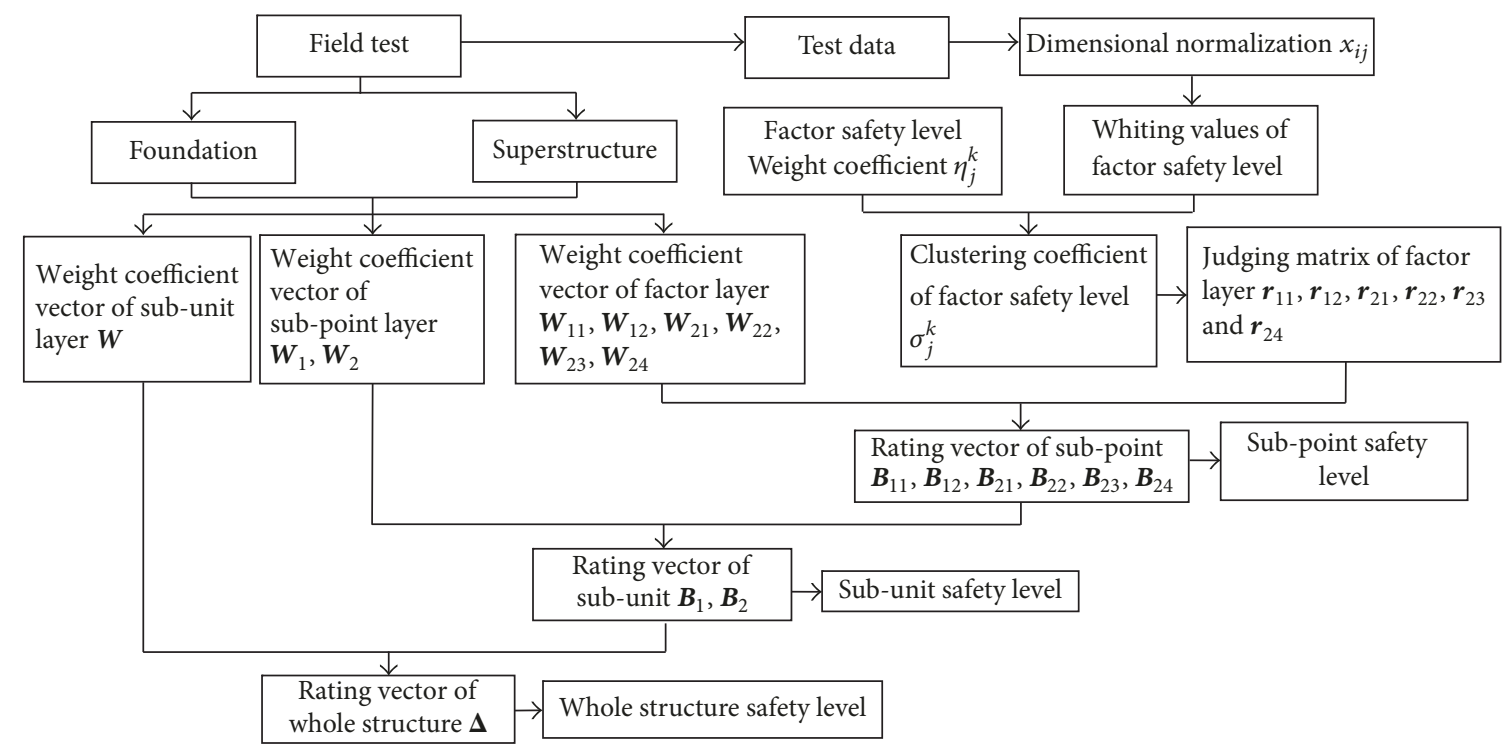

FIGURE 2: Evaluation procedure of the masonry structure safety.

TABLE 10: Brick and mortar strength (unit: MPa).

\begin{tabular}{lcc}
\hline Name & Position & Estimation value of strength \\
\hline \multirow{3}{*}{ Brick } & Floor 1 & MU10 \\
& Floor 2 & MU10 \\
& Floor 3 & MU7.5 \\
& Floor 4 & MU10 \\
\hline \multirow{3}{*}{ Mortar } & Floor 1 & 6.54 \\
& Floor 2 & 3.06 \\
& Floor 3 & 2.08 \\
& Floor 4 & 1.60 \\
\hline
\end{tabular}

calculating the dimensionless value of various factors, the whitening values were obtained by substituting the handling data into the whitening weight function. Then, the weight coefficients of various factors were counted. Finally, the evaluation matrix of the subgrade, foundation, wall and column, beam, floor slab, and parapet were determined, respectively, as follows:

$$
\begin{aligned}
& \mathbf{r}_{11}=\left[\begin{array}{llll}
0.22 & 0.78 & 0 & 0 \\
0.19 & 0.82 & 0 & 0 \\
0.32 & 0.68 & 0 & 0
\end{array}\right], \\
& \mathbf{r}_{12}=\left[\begin{array}{cccc}
0.27 & 0.73 & 0 & 0 \\
0.11 & 0.89 & 0 & 0 \\
0.32 & 0.68 & 0 & 0 \\
0 & 1.0 & 0 & 0
\end{array}\right], \\
& \mathbf{r}_{21}=\left[\begin{array}{cccc}
0.97 & 0 & 0 & 0.03 \\
0 & 1.0 & 0 & 0 \\
0.32 & 0.68 & 0 & 0 \\
0 & 1.0 & 0 & 0
\end{array}\right],
\end{aligned}
$$

$$
\begin{aligned}
& \mathbf{r}_{22}=\left[\begin{array}{cccc}
0.97 & 0 & 0 & 0.03 \\
0 & 1.0 & 0 & 0 \\
0.32 & 0.68 & 0 & 0 \\
0 & 1.0 & 0 & 0
\end{array}\right], \\
& \mathbf{r}_{23}=\left[\begin{array}{cccc}
0.27 & 0.73 & 0.1 & 0 \\
0.26 & 0.74 & 0 & 0 \\
0.11 & 0.89 & 0 & 0 \\
0 & 0 & 0 & 1.0
\end{array}\right], \\
& \mathbf{r}_{24}=\left[\begin{array}{cccc}
0 & 0 & 0.97 & 0.03 \\
0.11 & 0.89 & 0 & 0 \\
0.32 & 0.68 & 0 & 0 \\
0 & 0 & 0 & 1.0
\end{array}\right] .
\end{aligned}
$$

A full rating level analysis was performed to evaluate the effect of each factor (bearing capability of subgrade, uneven settlement of subgrade, stability of subgrade, bearing capability, structure, deformation and crack of the foundation, wall and column, beam, floor slab, and parapet) on the safety of each factor in subpoint level as shown in Figure 5. The plot demonstrates that, for all of the factors in the factor level, the most dangerous factors are the crack of floor slab and the crack of parapet, whose membership degree to $d_{\mathrm{u}}$ is 1.0. The following factor is the bearing capability of the parapet, which has a 0.97 membership degree to $c_{\mathrm{u}}$. Therefore, the parapet and the floor slab need immediate repair corresponding to the standard (GB50292-1999) [7]. For other factors, the evaluation levels is at least $b_{\mathrm{u}}$ with a membership degree of 0.68 , which means that their safety is just a little less than required according to the standard and does not need repair 

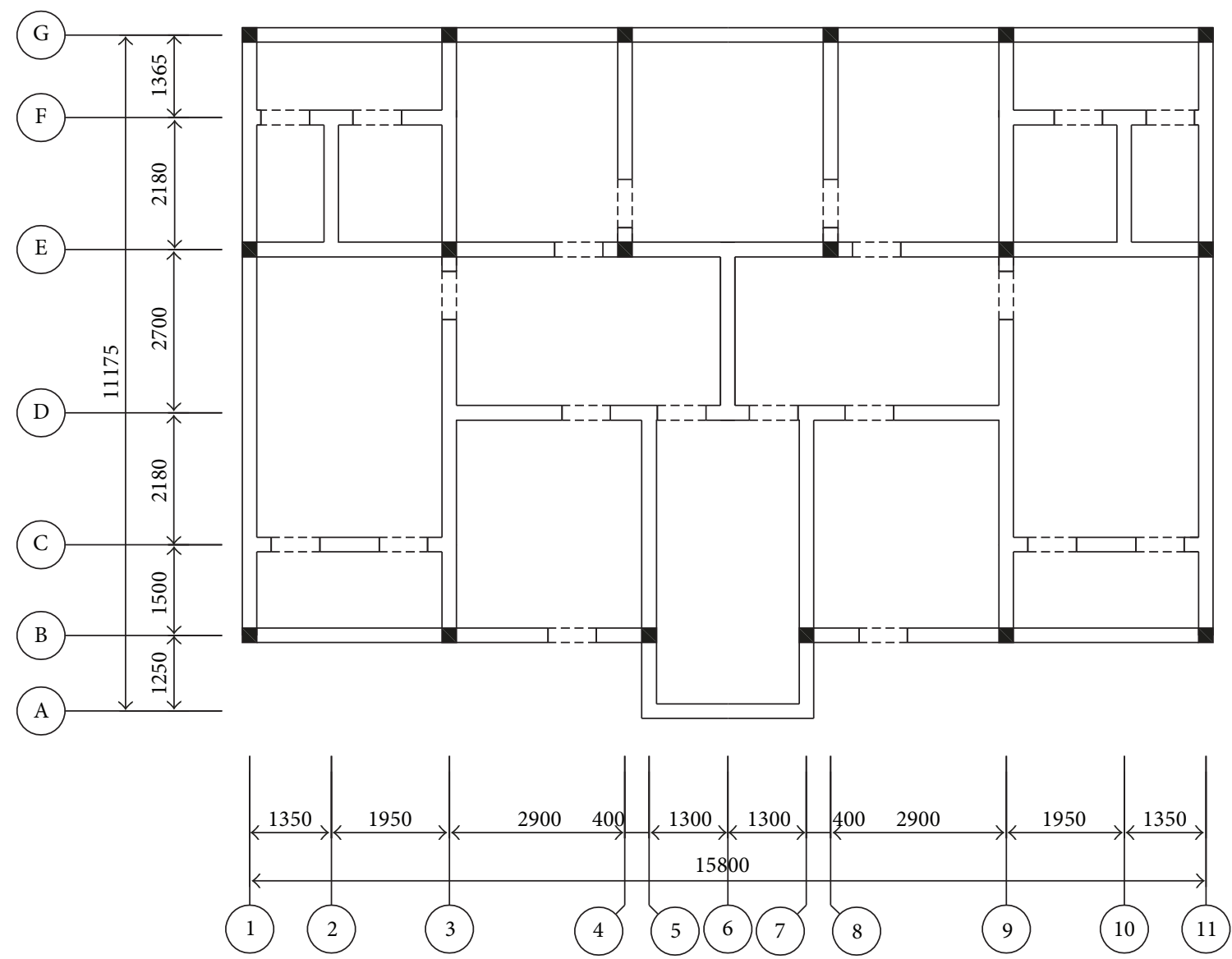

FIGURE 3: The structural plane layout.

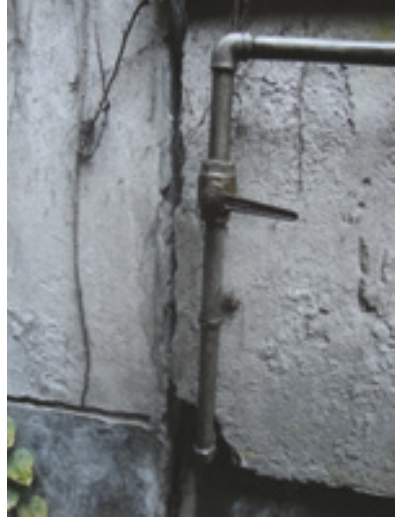

(a) Wall joint cracking

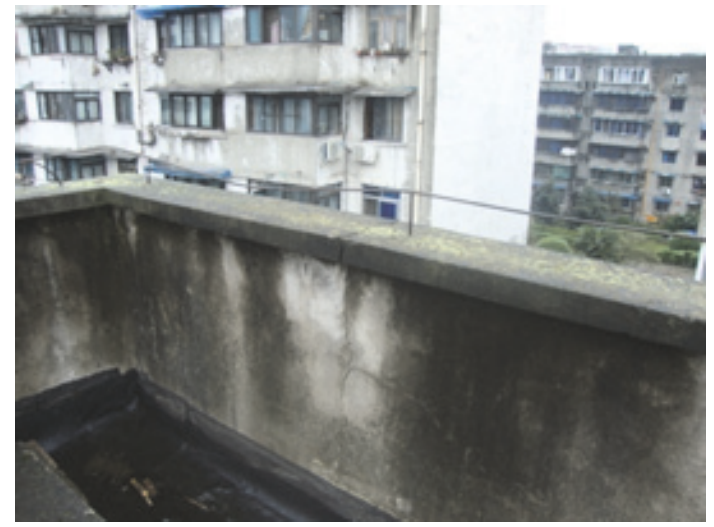

(b) Parapet cracking

Figure 4: The structural damage.

yet. Also, for these factors, they have some membership degree to level $a_{\mathrm{u}}$.

\subsection{Fuzzy Comprehensive Evaluation}

3.2.1. Fuzzy Comprehensive Evaluation of the Subpoint Layer. Based on the fuzzy weight vector $\mathbf{W}_{i j}$ and the judgment matrix $\mathbf{r}$ for the factor layer, we could get the rating vector of the subpoint layer factors according to formulas (1). The results are $\mathbf{B}_{11}=\mathbf{W}_{11} * \mathbf{r}_{11}=\left[\begin{array}{llll}0.274 & 0.726 & 0 & 0\end{array}\right] ; \mathbf{B}_{12}=$ $\mathbf{W}_{12} * \mathbf{r}_{12}=\left[\begin{array}{llll}0.201 & 0.799 & 0 & 0\end{array}\right] ; \mathbf{B}_{21}=\mathbf{W}_{21} * \mathbf{r}_{21}=$ $\left[\begin{array}{llll}0.522 & 0.463 & 0 & 0.015\end{array}\right] ; \quad \mathbf{B}_{22}=\mathbf{W}_{22} * \mathbf{r}_{22}=$ $\left[\begin{array}{llll}0.522 & 0.463 & 0 & 0.015\end{array}\right] ; \mathbf{B}_{23}=\mathbf{W}_{23} * \mathbf{r}_{23}=$ $\left[\begin{array}{llll}0.174 & 0.357 & 0 & 0.239\end{array}\right] ; \mathbf{B}_{24}=\mathbf{W}_{24} * \mathbf{r}_{24}=$ $\left[\begin{array}{llll}0.073 & 0.214 & 0.461 & 0.252\end{array}\right]$. The results are shown in Figure 6. 

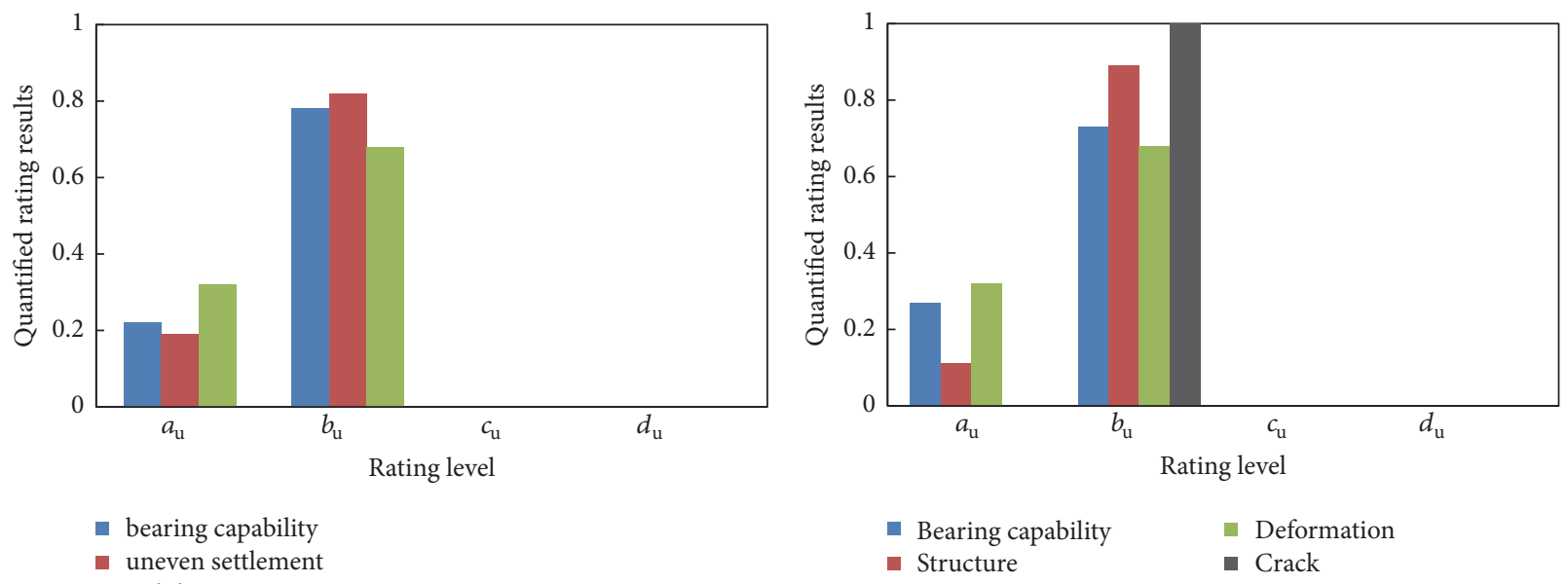

(a) Subgrade

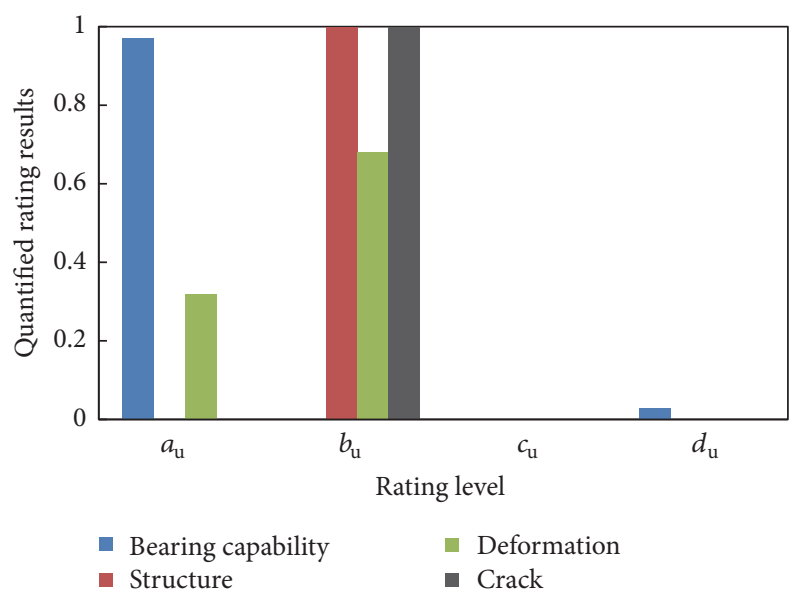

(c) Wall and column

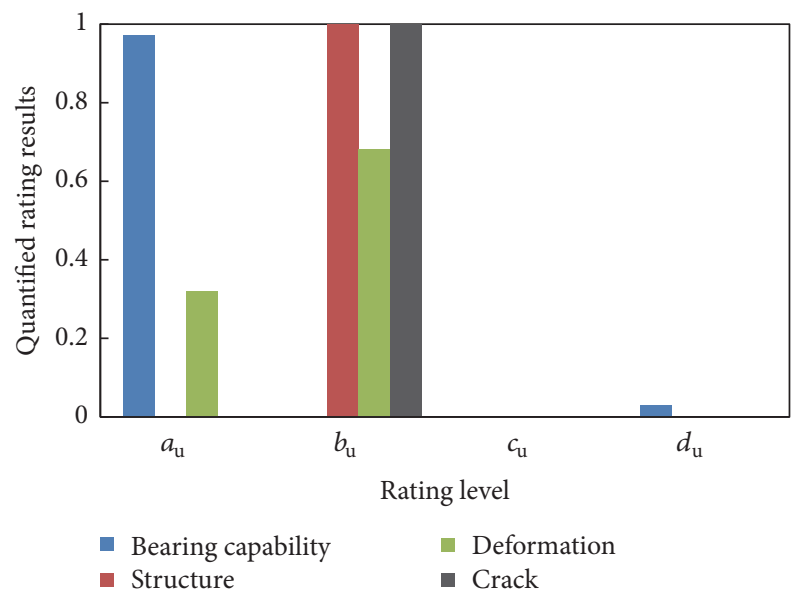

(d) Beam

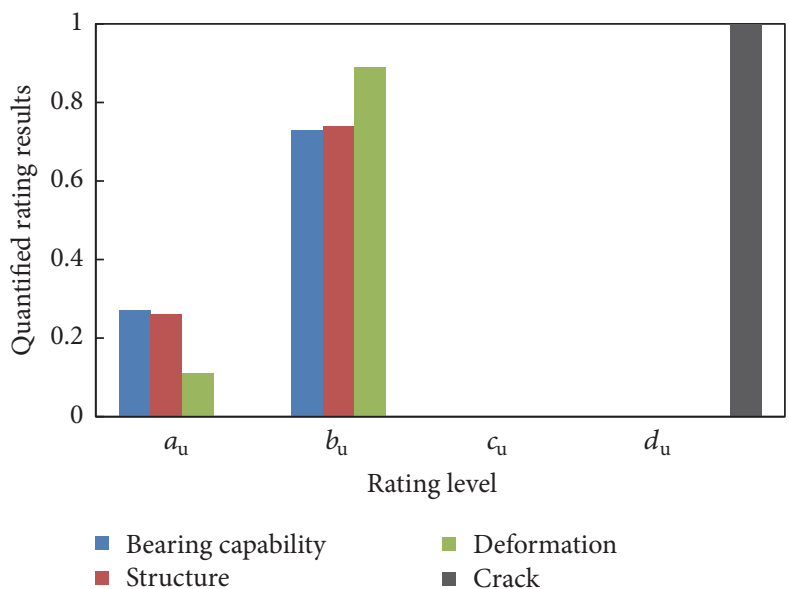

(e) Floor slab

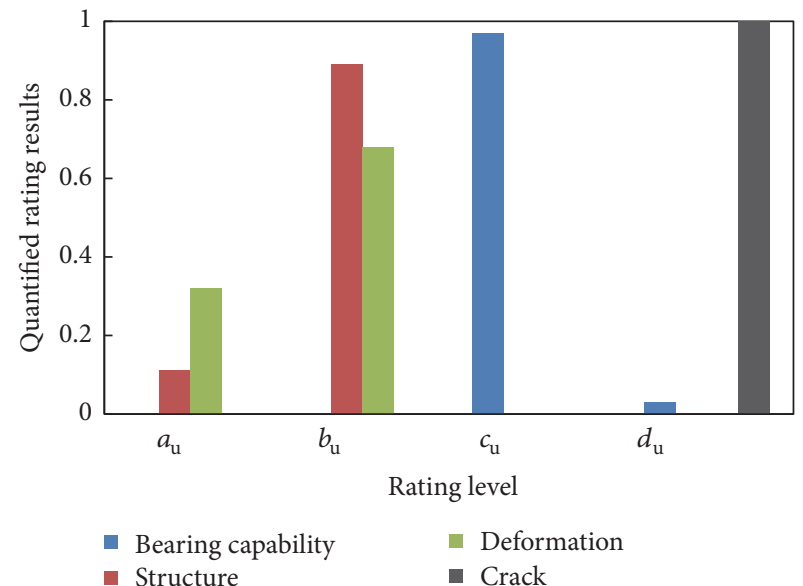

(f) Parapet

FIGURE 5: The evaluation results of the factor level.

It can be seen that the safety grade of subgrade, foundation, wall and column, beam, floor slab, and parapet are $B_{\mathrm{u}}, B_{\mathrm{u}}, A_{\mathrm{u}}, A_{\mathrm{u}}, B_{\mathrm{u}}$, and $C_{\mathrm{u}}$, respectively. The results of the subpoint level are based on the factor level so that in this level the most dangerous factors are also floor slab and parapet.
Again, except for parapet and floor slab, all of the remaining factors not only possess membership degree to level $B_{\mathrm{u}}$ but also to level $A_{\mathrm{u}}$. That is to say although the safeties of these factors are a little less than required, it is positive to say they still have some safety storage capacity. 


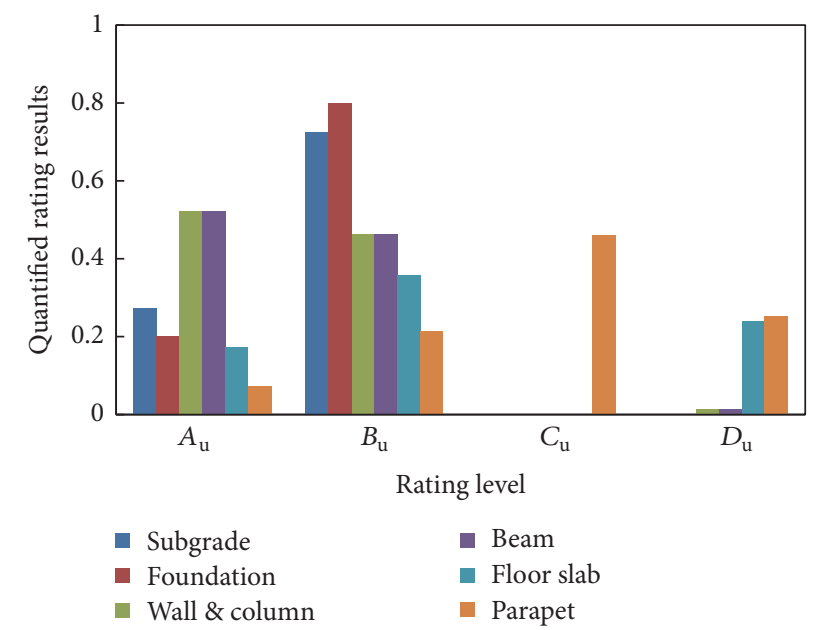

FIGURE 6: The evaluation results of level subpoint.

3.2.2. Fuzzy Comprehensive Evaluation for Subunit Layer. The evaluation matrix $R_{i}$ of subitem layer was constructed based on formulas (2) as follows:

$$
\begin{aligned}
& \mathbf{R}_{1}=\left[\begin{array}{llll}
0.27 & 0.73 & 0 & 0 \\
0.20 & 0.80 & 0 & 0
\end{array}\right], \\
& \mathbf{R}_{2}=\left[\begin{array}{llll}
0.52 & 0.46 & 0 & 0.02 \\
0.52 & 0.46 & 0 & 0.02 \\
0.17 & 0.36 & 0 & 0.24 \\
0.07 & 0.21 & 0.46 & 0.25
\end{array}\right] .
\end{aligned}
$$

Then, according to formula (3), the rating vectors of subunit layer are $\mathbf{B}_{1}=\left[\begin{array}{ll}0.241 & 0.759\end{array}\right], \mathbf{B}_{2}=$ $\left[\begin{array}{llll}0.432 & 0.428 & 0.034 & 0.066\end{array}\right]$, respectively. The results are shown in Figure 7.

It is obvious that the safety grade of foundation and superstructure are $B_{\mathrm{u}}$ and $A_{\mathrm{u}}$, respectively. Based on the results of the subpoint level, the results of the subunit level are similar. But the safety storage capacity of the superstructure is bigger than that of the foundation since its membership degree to $A_{\mathrm{u}}$ is larger.

3.2.3. Fuzzy Comprehensive Evaluation of the Target Layer. The evaluation matrix $\mathbf{R}$ of subunit layer, which was constructed based on formula (4), is shown as follows:

$$
\mathbf{R}=\left[\begin{array}{cccc}
0.241 & 0.759 & 0 & 0 \\
0.432 & 0.428 & 0.034 & 0.066
\end{array}\right]
$$

Then, according to formula (5), overall rating vector is $\Delta=\left[\begin{array}{llll}0.327 & 0.610 & 0.015 & 0.048\end{array}\right]$. The results are shown in Figure 8.

As can be seen from Figure 8, the safety grade of the whole structure is $B_{\text {su }}$ with a membership of 0.610 and also with a membership degree of 0.327 to $A_{\text {su }}$, which means that although the safety level of this building is the second level, a safety storage capability of $32.7 \%$ of this building can be estimated.
3.3. Contrast with the Results of Current Standard Method. Table 11 indicates the contrast of the evaluation results of this building according to the standard method and the proposed method in this paper. It can be seen from Table 11 that the results of these two methods are totally identical, which verifies the accuracy of the proposed method. Moreover, the method of this paper is capable of obtaining the membership degree of every factor in every layer in Figure 1 so that we are able to get more information from its results as shown above.

Based on the above analysis, in this case, the safety of the whole structure is $B_{\text {su }}$ with a safety storage capability of $32.7 \%$. The subgrade and foundation in the subpoint layer are the most important structural members contributing to the safety of the whole structure. And the most dangerous factors that affect the whole safety are the crack of the parapet and the floor slap, and the bearing capability of the parapet should also be noticed.

\section{Conclusion}

(1) In this paper, a four-layer hierarchical evaluation model of masonry structure including target layer, subunit, subpoint, and factor layer is constructed according to the structural characteristic described in the standard (GB 50292-1999). A three-level fuzzy evaluation model for safety evaluating is proposed based on the AHP theory. It is proved that AHP is an effective method to stratify and classify the safety influencing factors of masonry structure.

(2) On the basis of grey clustering theory, the whitening weight function for every factor in the factor layer is constructed based on their clear or fuzzy evaluating grades in the standard to obtain the clustering coefficients. Moreover, the evaluation matrixes of the factor layer, which would be used in the three-level fuzzy evaluation model, are acquired by mathematical transformation of the clustering coefficients. Therefore, the influence of various effective factors to the structural members on the safety of masonry structure is multiangle comprehensive revealed, which also proves the applicability of grey clustering theory on safety evaluation.

(3) A comprehensive evaluation method combining AHP and Grey approach is put forward. Its applicability and feasibility are verified by an engineering example. The results show that the proposed method is able to quantitatively evaluate the safety of each unit composed of the masonry structure, each structure member composed of the unit, and each factor that affects the safety of the structure members. The method also makes it pretty easy to find the most dangerous factor and to estimate the safety storage capability of the existing building, which may facilitate the following reinforcing program.

\section{Conflicts of Interest}

The authors declared no potential conflicts of interest with respect to the research, authorship, and/or publication of this article. 


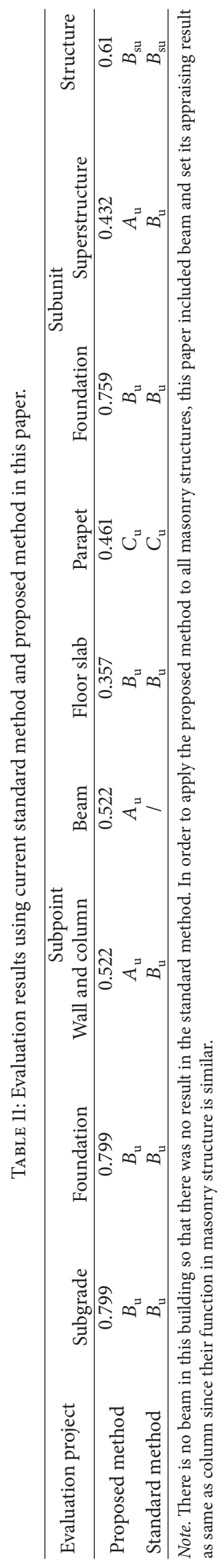




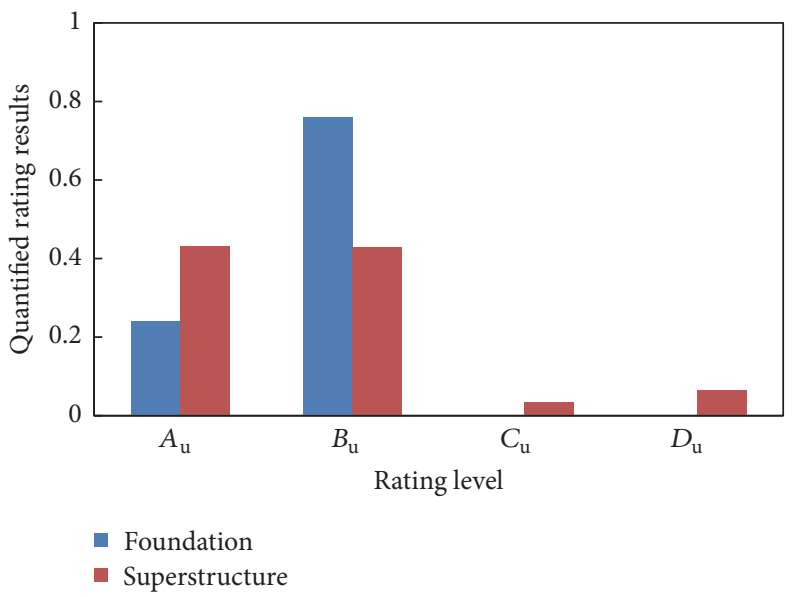

FIgURE 7: The evaluation results of level subunit.

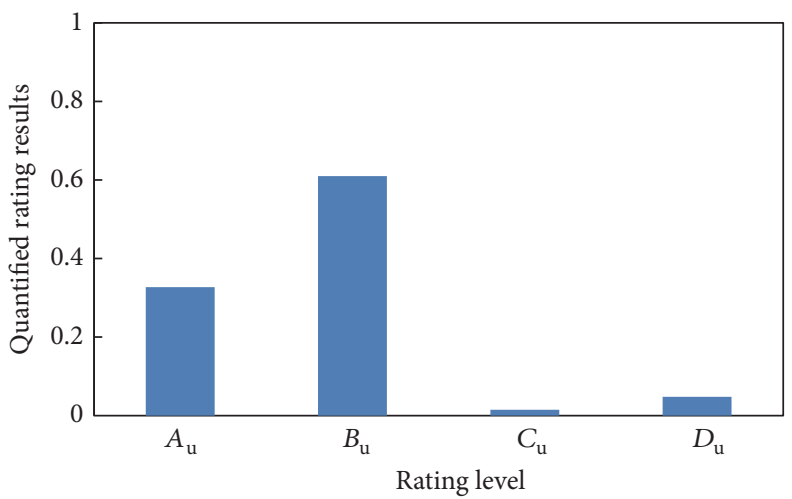

- Structure

FIGURE 8: The evaluation results of the structure.

\section{Acknowledgments}

The authors disclosed receipt of the following financial support for the research, authorship, and/or publication of this article: this research was supported by China National Key Research and Development Program (2016YFC0802205).

\section{References}

[1] E. Bertolesi, G. Milani, F. G. Carozzi, and C. Poggi, "Ancient masonry arches and vaults strengthened with TRM, SRG and FRP composites: Numerical analyses," Composite Structures, vol. 187, pp. 385-402, 2018.

[2] G. Milani, "Lesson learned after the Emilia-Romagna, Italy, 2029 May 2012 earthquakes: A limit analysis insight on three masonry churches," Engineering Failure Analysis, vol. 34, pp. 761778,2013

[3] C. Fagundes, R. Bento, and S. Cattari, "On the seismic response of buildings in aggregate: Analysis of a typical masonry building from Azores," Structures, vol. 10, pp. 184-196, 2017.

[4] R. Maio, J. M. C. Estêvão, T. M. Ferreira, and R. Vicente, “The seismic performance of stone masonry buildings in Faial island and the relevance of implementing effective seismic strengthening policies," Engineering Structures, vol. 141, pp. 41-58, 2017.
[5] M. Valente and G. Milani, "Seismic assessment of historical masonry towers by means of simplified approaches and standard FEM," Construction and Building Materials, vol. 108, pp. 74-104, 2016.

[6] S. Casolo, G. Milani, G. Uva, and C. Alessandri, "Comparative seismic vulnerability analysis on ten masonry towers in the coastal Po Valley in Italy," Engineering Structures, vol. 49, pp. 465-490, 2013.

[7] GB50292-1999, Standard for appraiser of reliability of civil building, National Standards of People's Republic of China, 1999 (In Chinese).

[8] C.-M. Liu and X.-L. Liu, "Study on the comprehensive assessment method of structural reliability," Building Science Research of Sichuan, vol. 30, no. 4, pp. 46-48, 2004 (Chinese).

[9] X.-L. Gu, S.-J. Chen, and W. P. Zhang, "An applicable method to assess the reliability of existing building structures," Structural Engineering International, vol. 23, no. 4, pp. 12-16, 2007 (Chinese).

[10] Y. Lin, X. Qiu, and Y. Ge, "Fuzzy comprehensive evaluation method for masonry structure safety," Journal of Southwest Jiaotong University, vol. 51, no. 6, pp. 1214-1221, 2016 (Chinese).

[11] G. Raviv, A. Shapira, and B. Fishbain, "AHP-based analysis of the risk potential of safety incidents: case study of cranes in the construction industry," Safety Science, vol. 91, pp. 298-309, 2017. 
[12] L. A. Zadeh, "Fuzzy sets," Information and Control, vol. 8, no. 3, pp. 338-353, 1965.

[13] X. Chen, Y. Liu, and Y. Liu, “The fire vulnerability evaluation of the old building based on fuzzy comprehensive assessment method," AER-Advances in Engineering Research, vol. 27, pp. 642-647, 2015.

[14] S.-F. Liu and F. Jeffrey, "The current developing status on Grey system theory," Journal of Grey System, vol. 19, no. 2, pp. 111-113, 2007.

[15] J. L. Deng, "Introduction to grey system theory," The Journal of Grey System, vol. 1, no. 1, pp. 1-24, 1989.

[16] X.-P. Bai and Y.-N. Liu, "Reliability analysis on civil engineering project based on integrated adaptive simulation annealing and gray correlation method," Frontiers of Structural and Civil Engineering, vol. 10, no. 4, pp. 462-471, 2016.

[17] C.-X. Yu, Z.-G. Yu, Y.-Q. Zhao et al., "Application of grey system theory in the dynamic monitoring of bridge," in Procceedings of the 3rd International Conference on Civil Engineering and Transportation, China, 2013.

[18] M. I. Eshtaiwi, I. A. Badi, A. M. Abdulshahed, and T. E. Erkan, "Assessment of airport performance using the grey theory method," Grey Systems: Theory and Application, vol. 7, no. 3, pp. 426-436, 2017.

[19] L. Bai, H. Wang, C. Shi, Q. Du, and Y. Li, "Assessment of SIP buildings for sustainable development in rural China using AHP-grey correlation analysis," International Journal of Environmental Research and Public Health, vol. 14, no. 11, p. 1292, 2017.

[20] J. Yu, X. Zhang, and C. Xiong, "A methodology for evaluating micro-surfacing treatment on asphalt pavement based on grey system models and grey rational degree theory," Construction and Building Materials, vol. 150, pp. 214-226, 2017.

[21] W.-T. Wang and Z.-R. Liu, "The Study on Grey-hierarchy analysis in risk management of subway construction," Procedia Earth and Planetary Science, vol. 29, pp. 325-330, 2015.

[22] X.-J. Qiu, Research on fuzzy comprehensive evaluation method for safety of masonry structure based on Grey clustering [Master Thesis], Southwest JiaoTong University, China, 2016 (Chinese).

[23] Z.-Q. Luo and S.-L. Yang, "Comparative study on sever all scales in AHP," Systems Engineering Theory \& Practice, vol. 9, pp. 5160, 2004.

[24] GB50007-2011, Code for design of building foundation 2011, National Standards of People's Republic of China, 2011 (In Chinese).

[25] GB50003-2011, Code for design of masonry structures, National Standards of People's Republic of China, 2011 (In Chinese).

[26] GB 50011-2010, Code for seismic design of buildings, National Standards of People's Republic of China, 2010 (In Chinese). 


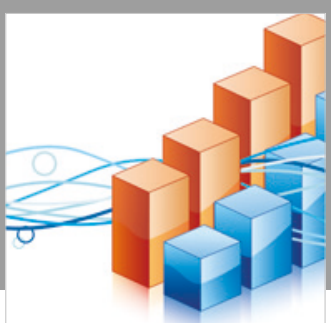

Advances in

Operations Research

\section{-n-m}
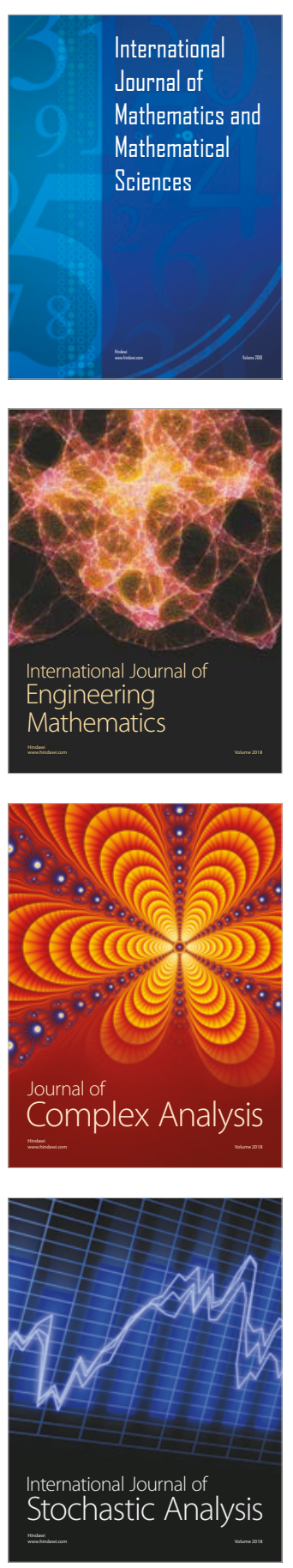
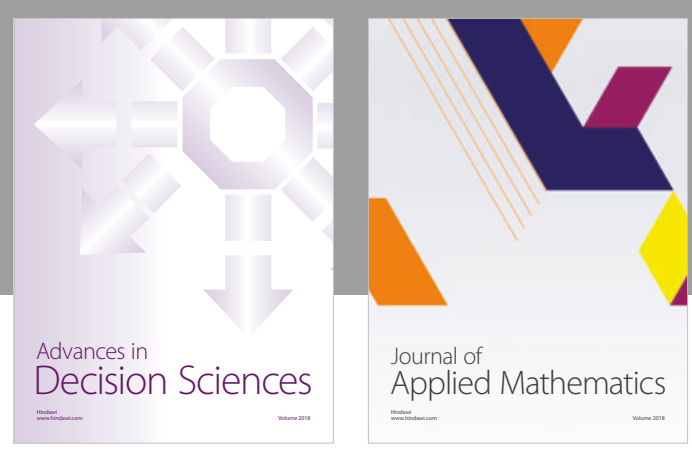

Journal of

Applied Mathematics
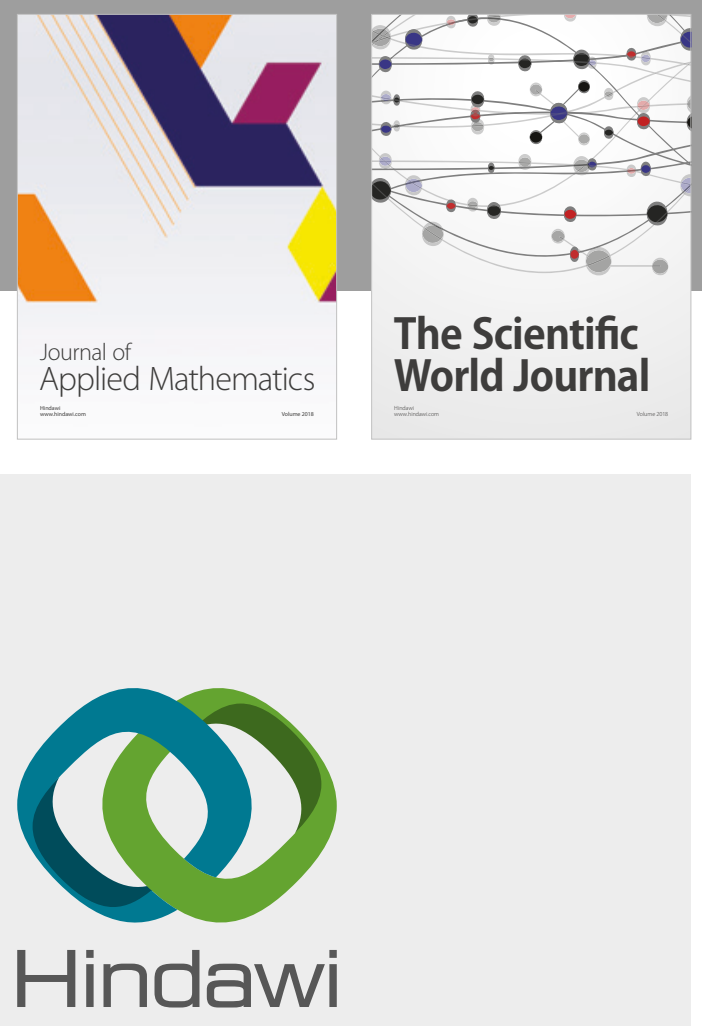

Submit your manuscripts at

www.hindawi.com

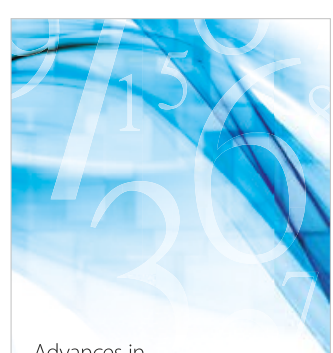

Advances in
Numerical Analysis
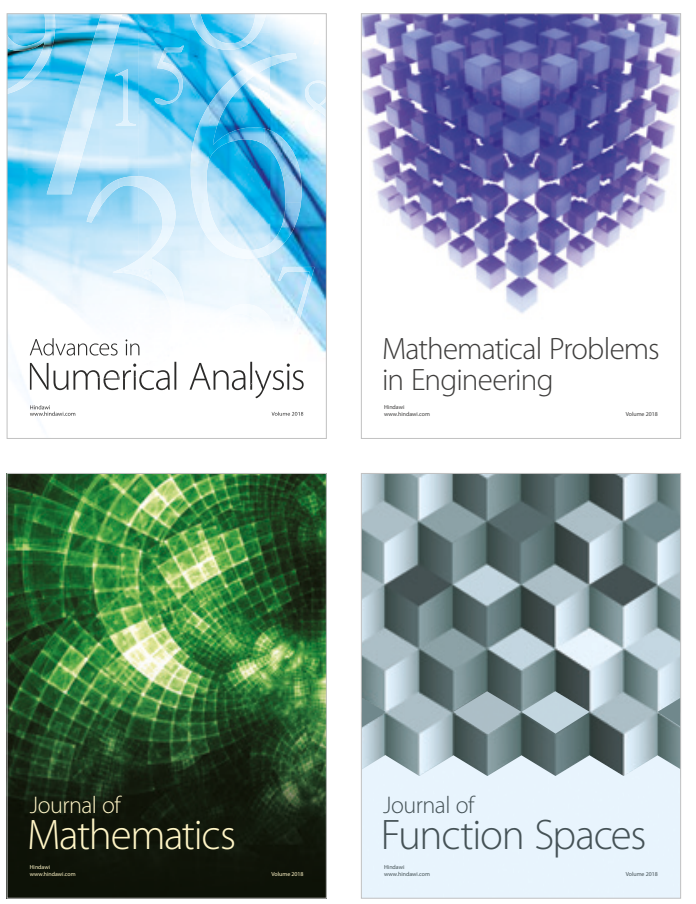

Mathematical Problems in Engineering

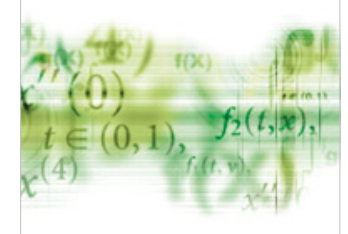

International Journal of

Differential Equations

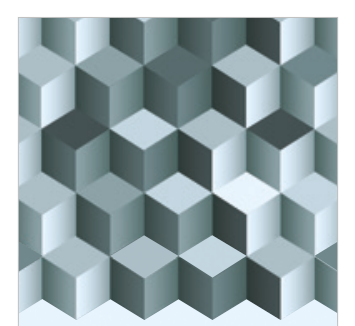

Journal of

Function Spaces

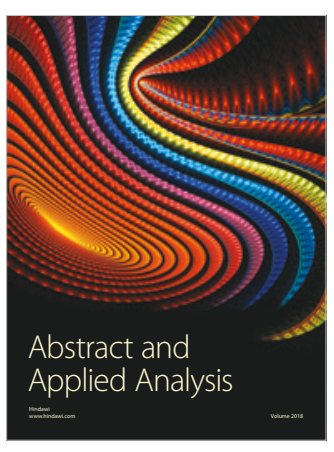

The Scientific

World Journal

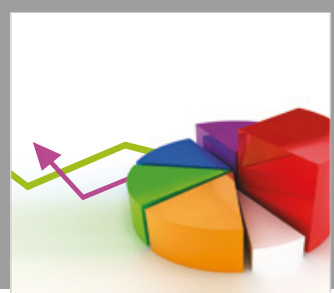

Journal of

Probability and Statistics
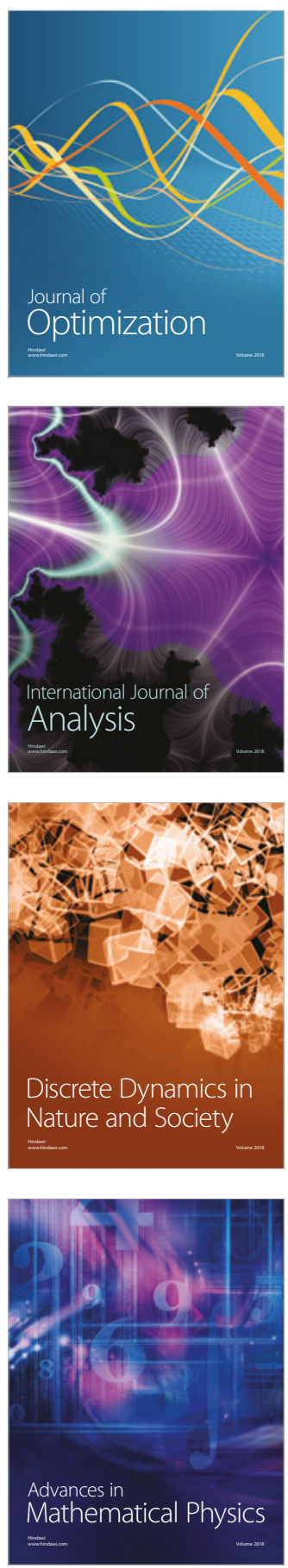